\title{
KARAKTERISASI POLIMER KONDUKTIF POLIPIROL BERPENGISI SERBUK BAN UNTUK MENDETEKSI KONDUKTIVITAS MINYAK
}

\author{
Satriaji Sudigdo, Rizky Dharmawan, Hamidah Harahap \\ Departemen Teknik Kimia, Fakultas Teknik, Universitas Sumatera Utara, \\ Jl. Almamater Kampus USU Medan 20155, Indonesia \\ Email: aji.digdo@gmail.com
}

\begin{abstract}
Abstrak
Sensor polimer konduktif dengan campuran polipirol, serbuk ban, dan 1,4-metil-pirolidinone telah dibuat dengan menggunakan proses polimerisasi. Proses polimerisasi dilakukan pada temperatur $100^{\circ} \mathrm{C}$ pada penangas air selama 30 menit. Analisa yang dilakukan pada sensor polimer konduktif tersebut antara lain Scanning Electron Microscopy (SEM), Fourier Transform Infrared (FTIR), dan X-Ray Diffraction (XRD). Analisa konduktivitas yang dilakukan menggunakan beberapa jenis minyak (minyak sawit, minyak jagung, solar, dan oli). Hasil analisa konduktivitas menunjukkan bahwa sensor ke-4 (mengandung 20 phr serbuk ban) dengan temperatur proses $80^{\circ} \mathrm{C}$ dengan waktu proses 30 menit memiliki nilai konduktivitas yang paling tinggi. Dari hasil analisa Scanning Electron Microscopy (SEM) menunjukkan bahwa permukaan sensor memiliki struktur yang kasar dan memiliki penyebaran serbuk ban yang merata. Hasil dari analisa X-Ray Diffraction (XRD) menunjukkan bahwa sensor memiliki struktur kristal Face Centered Cubic (FCC). Hasil tes konduktivitas terhadap minyak menunjukkan bahwa minyak jagung lebih reaktif dibandingkan yang lain.
\end{abstract}

Kata kunci : polipirol, serbuk ban, konduktivitas, polimer konduktif

\begin{abstract}
Conductive polymer sensor based polypyrrole (ppy) and tire dust and 1,4-methyl-pyrrolidinone was made by using polymerization process. The polymerization process was prepared at temperature $100^{\circ} \mathrm{C}$ in boiling water for 30 minutes. Conductive polymer sensor is undergone several type of analysis including electrical conductivity, Scanning Electron Microscopy (SEM), Fourier Transform Infrared (FTIR), and X-Ray Diffraction (XRD). The test used some kind of oil (palm oil,corn oil, diesel, and engine oil). The conductivity test result shows that sensor-4 (contain 20 phr of tire dust) in $80^{\circ} \mathrm{C}$ at 30 minutes had the highest conductivity. Scanning Electron Microscopy result shows the rough surface and well dispersed of tire dust in polypyrrole/tire dust blends. The XRD analysis shows the Face Centered Cubic (FCC) crystallographic structure of the sensor. The oil conductivity test shows that the corn oil is more reactive than others.
\end{abstract}

Key words : polypyrrole, tire dust, conductivity, conductive polymer

\section{Pendahuluan}

Polimer konduktif pertama kali diidentifikasi pada tahun 1980 dan termasuk dalam kelas bahan organik yang dapat disintesis elektrokimia dari monomer yang sesuai dan heterosiklik aromatik [2]. Polimer konduktif banyak menarik perhatian para peneliti dari berbagai cabang ilmu dan teknologi sebagai bahan baku elektroda untuk penyimpanan energi (baterai elektrokimia dan juga kapasitor), sebagai katalis elektrik, biosensor, membran pemisahan gas, pelindung anti korosif, dan lain - lain [1]. Sensor yang banyak dijumpai biasanya terbuat dari bahan-bahan anorganik (bahan kimia padat) yang mempunyai ikatan logam yang kuat sehingga tidak dapat terurai oleh lingkungan. Selain itu, sensor yang berasal dari bahan anorganik akan lebih merugikan karena setelah menyerap zat yang akan di analisa, sensor tersebut harus menggunakan bahan kimia atau suhu yang tinggi untuk mengeluarkan zat tersebut dari sensor. Untuk menyiasati masalah diatas, digunakanlah sensor yang berbahan dasar organik (polimer konduktif) yang dapat teruraikan oleh lingkungan. Salah satu bahan dasar yang dapat digunakan untuk pembuatan sensor ini adalah polipirol.

\section{Teori}

Polipirol (PPy) adalah salah satu bahan yang menjanjikan dalam penggunaan produk komersil dikarenakan sifat stabilitas lingkungannya yang baik, sintesis yang mudah, dan memiliki konduktivitas yang lebih tinggi dibanding polimer konduktif yang lain. Selain itu terdapat fakta bahwa monomer pirol mudah dioksidasi dan mudah larut dalam air [5]. 
Polpirol merupakan senyawa heterosiklik yang dapat disintesis secara elektrokimia dengan penambahan pengotor yang dapat meningkatkan konduktivitas listriknya. Polipirol merupakan senyawa dengan tekstur seperti bunga karang, terdekomposisi pada suhu $180-237^{\circ} \mathrm{C}$ dan memiliki temperatur kaca $160-170^{\circ} \mathrm{C}$, serta memiliki nilai konduktivitas dibawah $3 \mathrm{~S} \mathrm{~cm}^{-1}$. Polipirol biasanya sering digunakan sebagai biosensor, sensor gas, kabel, pelapis bahan anti listrik, kapasitor, baterai polimer, perlengkapan elektronik, membran fungsional, dan lain - lain [7].

\section{Bahan dan Metodologi \\ Bahan}

Bahan yang digunakan berupa polipirol, serbuk ban dengan ukuran 80 mesh, 1,4-metil pirolidinone, epoksi, bahan pengeras (hardener) yang diperoleh dari Sigma Aldrich Pulau Penang, Malaysia. PCB dan kabel diperoleh dari Laboratorium Sensor Universitas Malaysia Perlis.

\section{Metodologi}

\section{Pembuatan Sensor}

0,2 gram polipirol dicampur dengan $5 \mathrm{phr}$ (per hundred resin) serbuk ban pada beaker glass. Ditambahkan $10 \mathrm{ml}$ 1,4-Metilpyrroledinone. Campuran diaduk selama 25 menit diatas penangas air. Campuran ditambahkan dengan epoxy-hardener sebanyak $3 \mathrm{ml}$ dan diaduk hingga homogen. Campuran yang homogen kemudian diletakkan sebanyak $1 \mathrm{ml}$ pada PCB. Campuran yang telah melekat pada PCB dipanaskan dalam oven pada $70,80,90^{\circ} \mathrm{C}$ selama 20,30 , dan 40 menit. Setelah dikeluarkan dari oven, dilakukan posting-curing pada sampel selama 24 jam. Formulasi dari pembuatan sensor ditunjukkan dalam Tabel 1.

Tabel 1. Formulasi Pembuatan Sensor

\begin{tabular}{|c|c|c|c|}
\hline $\begin{array}{c}\text { Jenis } \\
\text { Sensor }\end{array}$ & $\begin{array}{c}\text { Polipirol } \\
\text { (gr) }\end{array}$ & $\begin{array}{c}\text { Serbuk } \\
\text { Ban } \\
\text { (phr) }\end{array}$ & $\begin{array}{c}\text { Epoxy- } \\
\text { hardener } \\
\text { (ml) }\end{array}$ \\
\hline Sensor-0 & 0,2 & - & 3 \\
\hline Sensor-1 & 0,2 & 5 & 3 \\
\hline Sensor-2 & 0,2 & 10 & 3 \\
\hline Sensor-3 & 0,2 & 15 & 3 \\
\hline Sensor-4 & 0,2 & 20 & 3 \\
\hline Sensor-5 & 0,2 & 25 & 3 \\
\hline
\end{tabular}

\section{Analisa Konduktivitas Sensor}

Dimasukkan Minyak goreng kualitas bagus sebanyak $50 \mathrm{ml}$ kedalam Erlenmeyer. Kemudian sensor yang telah dihubungkan ke multimeter di masukkan ke dalam Erlenmeyer yang berisi minyak sampai membasahi seluruh permukaan sensor. Tutup Erlenmeyer, lalu di ukur nilai resistansi pada alat multimeter. Dicatat hasil yang diperoleh. Dihitung dengan rumus :

$$
\sigma=\frac{T}{R \times A}
$$

Dimana: $\sigma=$ Nilai konduktifitas sensor $\mathrm{T}=$ Ketebalan dari PVC sensor $\mathrm{R}=$ Nilai resistansi sensor $\mathrm{A}=$ Luas permukaan sensor

\section{Analisa Gugus Fungsi (FTIR)}

Sensor dimasukkan ke dalam alat FT-IR. Dihitung panjang gelombang dengan menggunakan alat FT-IR tersebut. Resolusi spektrum yang dipilih dan jangkauan pemindaian adalah $4 \mathrm{~cm}^{-1}$ dan $600-4000 \mathrm{~cm}^{-1}$

\section{Analisa Morfologi Permukaan (SEM)}

Morfologi permukaan polipirol/ serbuk ban diteliti dengan menggunakan mikroskop elektron scanning Model Joel JSM 6460LA-. Sampel yang diuji merupakan sampel yang diproses pada temperatur 70,80 , dan $90^{\circ} \mathrm{C}$ untuk melihat struktur permukaan sensor. Sebelum pemeriksaan SEM, sensor di coating dengan lapisan Paladium tipis $20 \mathrm{~nm}$.

\section{Analisa $X$-Ray Diffraction}

Pengujian XRD pada sensor konduktif polimer dilakukan menggunakan XRD 6000 Shimadzu pada voltase $35 \mathrm{kV}, 25 \mathrm{~mA}$, dan radiasi $\mathrm{Cu}$. Pancaran dijalankan dalam rentang 10-80 (20). Analisa ini dilakukan pada suhu kamar mengunakan kecepatan sinar pada $5^{\circ} \mathrm{C} /$ menit.

\section{Hasil dan Pembahasan}

Berdasarkan hasil pengukuran nilai konduktivitas dimana diperoleh kondisi proses terbaik pembuatan sensor polimer konduktif, nilai konduktivitas tertinggi diperoleh pada temperatur $80{ }^{\circ} \mathrm{C}$ dengan waktu 30 menit. Pengaruh kandungan serbuk ban pada sensor terhadap nilai konduktivitasnya pada Gambar 1.

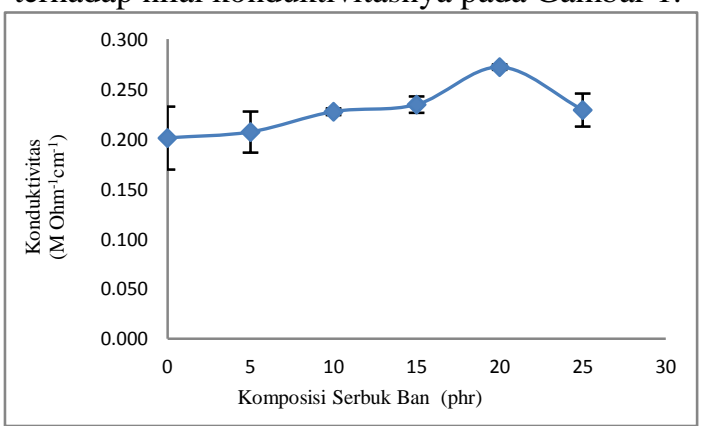

Gambar 1. Pengaruh Kandungan Serbuk Ban Terhadap Konduktivitas Sensor 
Dari hasil yang diperoleh, terlihat bahwa sensor yang tidak berpengisi serbuk ban (tire dust) memiliki konduktivitas yang lebih rendah dibandingkan dengan sensor yang berpengisi serbuk ban (tire dust). Kemudian dari Gambar 1 terlihat bahwa nilai konduktivitas sensor meningkat seiring dengan penambahan kosentrasi serbuk ban sebesar 5, 10, 15, dan 20 phr sebelum akhirnya mengalami penurunan nilai konduktivitas pada saat penambahan serbuk ban sebesar 25 phr. Peningkatan nilai konduktivitas disebabkan karena kandungan karbon hitam (carbon black) yang ada pada serbuk ban menyebabkan elektron yang ada pada polipirol lebih mudah untuk melakukan lompatan elektron disepanjang rantai polimer tersebut [6].

Gambar 2 menunjukkan hasil analisa gugus fungsi dari sensor dilakukan dengan menggunakan teknik ATR-FTIR untuk mengidentifikasi gugus fungsi dari senyawa polipirol murni dan juga untuk mengidentifikasi gugus fungsi pada sensor.

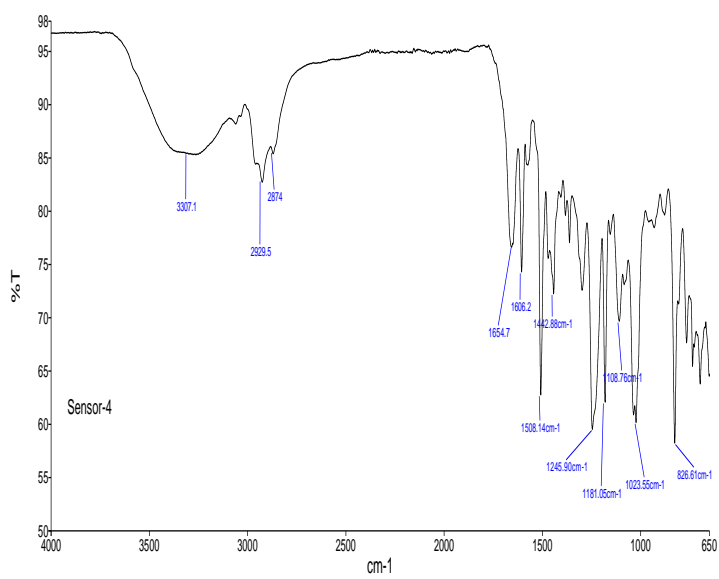

Gambar 2. Hasil Spektrum Sensor

Panjang gelombang 3307,1 $\mathrm{cm}^{-1}$ menunjukkan gugus O-H (hidroksil) yang berasal dari senyawa aditif dalam serbuk ban. Penyerapan pada panjang gelombang 2929,5, $2874 \mathrm{~cm}^{-1}$ adalah $\mathrm{C}-\mathrm{H}, \mathrm{CH}_{3}$, dan $\mathrm{CH}_{2}$. Panjang gelombang pada 1654,$7 ; 1606,2 ; 1508,14 \mathrm{~cm}^{-1}$ merupakan ikatan dari $\mathrm{C}=\mathrm{C}$ yang berasal dari struktur benzena didalam polipirol [4]. Penyerapan dengan panjang gelombang 1442,88 $\mathrm{cm}^{-1}$ menunjukkan keberadaan dari senyawa metal oksida [3] yang dapat berasal dari zink oksida yang terkandung pada serbuk ban. Penyerapan pada panjang gelombang 1245,90 $\mathrm{cm}^{-1}$ adalah amina primer $(\mathrm{N}-\mathrm{H})$. Panjang gelombang 826,61 $\mathrm{cm}^{-1}$ merupakan ikatan $\mathrm{C}-\mathrm{H}$ diluar dari struktur (out of plane) [4].

Gambar 3 merupakan hasil dari morfologi permukaan sensor polipirol berpengisi serbuk ban yang telah dianalisa dengan menggunakan
Scanning Electron Microscopy (SEM) dengan menggunakan perbesaran 200x.

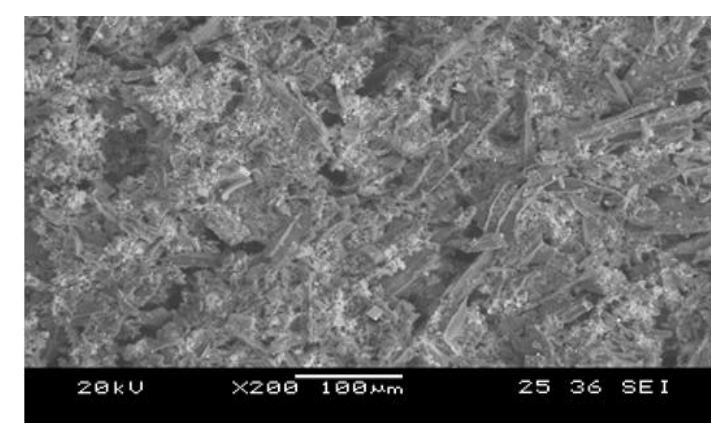

Gambar 3. Hasil SEM dengan perbesaran 200x

Berdasarkan hasil analisa morfologi permukaan dari sensor dengan kandungan serbuk ban sebesar 20 phr dengan temperatur pemrosesan $80^{\circ} \mathrm{C}$ selama 30 menit, terlihat bahwa distribusi partikel terlihat merata, hal ini ditunjukkan dengan terbentuknya agregat (kumpulan) yang menandakan bahwa serbuk ban telah terserap ke dalam polipirol, dengan tersebarnya partikel di dalam polimer konduktif, akan menjadikan lompatan - lompatan elektron pada sensor lebih baik. Dengan lompatan elektron yang lebih baik, maka nilai konduktivitas dari sensor akan meningkat. Gambar 4 menunjukkan karakteristik struktur dari sensor dengan kandungan serbuk ban sebesar 20 phr yang diproses pada temperatur $80^{\circ} \mathrm{C}$ selama 30 menit yang telah dianalisa dengan X-Ray Diffraction.

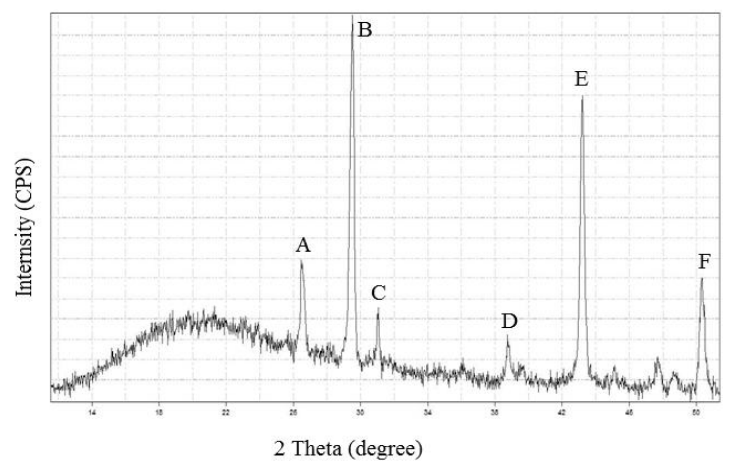

Gambar 4. Hasil Difraktogram Analisa X-Ray Diffraction

Berdasarkan hasil yang diperoleh dari Gambar 4, struktur kristal dari sensor dapat diketahui dengan mengkalkulasikan sumbu sumbu koordinat dari struktur kristalnya.

Dari Gambar 4 diketahui bahwa struktur kristal berdasarkan pola sistem kubik menunjukkan pola struktur Face Centered Cubic (FCC).

Gambar 5 menunjukkan nilai konduktivitas pada minyak yang dilakukan dengan menggunakan beberapa jenis minyak, 
seperti minyak goreng kelapa sawit dengan merek dagang Neptune, minyak jagung dengan merek dagang VeCorn, minyak solar, dan juga oli. Analisa ini dilakukan dengan menggunakan temperatur kamar $\left(30^{\circ} \mathrm{C}\right)$.

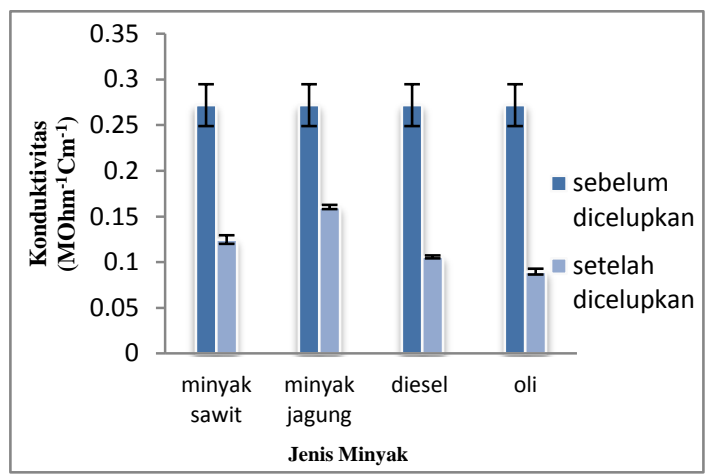

Gambar 5. Hasil Analisa Konduktivitas Pada Minyak

Dari Gambar 5 terlihat bahwa minyak dapat terdeteksi dengan menggunakan sensor ini. Hal ini disebabkan karena sensor yang dihasilkan merupakan pencampuran dari senyawa polipirol yang bersifat hidrofilik dan juga serbuk ban yang bersifat hidrofobik, sehingga sensor ini masih dapat mendeteksi senyawa minyak yang bersifat hidrofobik. Sensor yang dibuat pada penelitian ini memiliki kereaktifan yang lebih baik untuk digunakan pada minyak jagung dan juga minyak sawit. Hal ini dipengaruhi oleh ikatan rantai karbon yang terdapat pada masing - masing minyak. Minyak goreng sawit dan jagung memiliki ikatan rantai karbon yang lebih pendek dibandingkan minyak diesel dan juga oli. Komposit yang dihasilkan akan bereaksi dengan ikatan senyawa karbon untuk membentuk senyawa radikal yang akhirnya akan memungkinkan terjadinya lompatan elektron pada ikatan rantai karbon di dalam minyak tersebut. Sensor yang berasal dari polpirol berpengisi serbuk ban lebih reaktif terhadap minyak jagung dengan nilai konduktivitas sebesar $0,1605 \mathrm{M} \mathrm{ohm}^{-1} \mathrm{~cm}^{-1}$ Oleh karena itu, sensor ini lebih sesuai untuk mendeteksi minyak jagung.

\section{Kesimpulan}

Sensor yang menghasilkan nilai konduktivitas terbaik adalah sensor dengan kandungan serbuk ban sebesar 20 phr dengan suhu proses $80^{\circ} \mathrm{C}$ selama 30 menit. Dengan nilai konduktivitasnya sebesar $0,272 \mathrm{M} \mathrm{ohm} \mathrm{cm}^{-1}$. Dari hasil analisa FTIR terlihat bahwa ikatan antara matriks dan pengisi yang dihasilkan hanya berupa interaksi yang memberikan nilai konduktivitas pada sensor. Berdasarkan uji XRD sensor konduktif polipirol berpengisi serbuk ban yang dihasilkan memiliki struktur kristal FCC
(Face Centered Cubic). Sensor yang dibuat lebih menunjukkan kereaktifan terhadap minyak jagung dengan nilai konduktivitas sebesar 0,1605 $\mathrm{M} \mathrm{ohm} \mathrm{cm}^{-1}$.

\section{Daftar Pustaka}

[1] Efimov O N, Vernitskaya T V. 1997. Polypyrrole: a conducting polymer; its synthesis, properties and applications. Russian Academy of Sciences and Turpion Ltd.

[2] Julian W.G., Philip N.B. 1995. Application of Conducting Polymer Technology in Microsystem. Sensors and Actuators A, 51, halaman 57-66.

[3] Murugendrappa M V, Syed Khasim, M V N Ambika Prasad. 2005. Synthesis, Characterization and Conductivity Studies of Polypyrrole-Fly Ash Composites. Bull. Mater. Sci,. Vol.28, No.6, October 2005, pp. 565-569. Indian Academy of Science.

[4] Pavia Donald L, Gary M. Lampman, George S. Kriz. 2001. Introduction to Spectroscopy. Third Edition. Thomson Learning, Inc. United State of America.

[5] Qomariyah, Susi Nur. 2011. Pengembangan Sensor Alkohol dari Bahan Polipirol Konduktif dengan Variasi Konsentrasi Dopan Flouroborat. Fakultas Matematika dan Ilmu Pengetahuan Alam. Universitas Jember.

[6] Supri Abdul Ghani, Heah Cheng Yong. 2010. Development Of Carbon whiteCarbon Black-Polyaniline Composites As A Conductive Polymer. Journal of Physical Science.

[7] Wang, Lin-Xia., Xin-Gui Li, Yu-Liang Yang. 2001. Preparation, properties and applications of polypyrroles. 